\title{
A cladistic analysis of Graecopithecus
}

\section{AUTHORS: \\ Julien Benoit ${ }^{1}$ \\ Francis J. Thackeray ${ }^{1}$}

\section{AFFILIATION:}

${ }^{1}$ Evolutionary Studies Institute, School of Geosciences, University of the Witwatersrand, Johannesburg, South Africa

\section{CORRESPONDENCE TO: Julien Benoit}

EMAIL:

julien.benoit@wits.ac.za

\section{KEYWORDS:}

Hominini; Africa;

palaeobiogeography

\section{HOW TO CITE:}

Benoit J, Thackeray FJ.

A cladistic analysis of

Graecopithecus. S Afr J

Sci. 2017;113(11/12), Art.

\#a0238, 2 pages. http://dx.doi. org/10.17159/sajs.2017/a0238

(C) 2017. The Author(s).

Published under a Creative

Commons Attribution Licence.
Fuss et al. ${ }^{1}$ have recently claimed that the earliest Hominini - and incidentally the whole evolutionary root of humankind - could be found, not in Africa, but in Europe. This claim was critically discussed by the media in a number of articles 2,3 .

This new hypothesis was proposed on the basis of the re-assessment of a mandible and lower fourth premolars $\left(\mathrm{p}_{4}\right)$ from Greece and Bulgaria attributed to Graecopithecus freybergi and cf. Graecopithecus sp., respectively. ${ }^{1}$ Based on an X-ray tomographic revision of this material, Fuss et al. ${ }^{1}$ found that Graecopithecus shares with Hominini a partial fusion of the $p_{4}$ buccal roots (a state that resembles Tomes' root in modern humans), thick enamel and megadonty. Graecopithecus fossils were dated to around 7.2 million years, which would make them the oldest remains attributed to Hominini, even older than Sahelanthropus tchadensis dated at around 6-7 million years.

However, none of the characters cited by Fuss et al. ${ }^{1}$ is strictly unique to Hominini, as thick enamel and megadonty are found in a wide variety of Miocene apes as well as in extant Pongo ${ }^{4,5} \mathrm{~A}$ partial fusion of $\mathrm{p}_{4}$ roots is present in 2-5\% of Pan specimens, as acknowledged by Fuss et al. ${ }^{1}$ These findings put the assertion that Graecopithecus belongs to Hominini into serious question.

Even if Graecopithecus can be attributed to Hominini, the fact that it is older than Sahelanthropus does not make it the basal-most representative of this clade. As recently exemplified by the Homo naledi case ${ }^{7}$, the stratigraphic age of a fossil taxon is not a reliable indicator of its phylogenetic position ${ }^{8}$. Fuss et al. ${ }^{1}$ emphasised the fact that Graecopithecus appears to be more derived than Sahelanthropus, both in terms of canine reduction and the degree of $p_{4}$ roots fusion. If Graecopithecus happens to be more derived than Sahelanthropus, then the evolutionary tree of Hominini would remain rooted in Africa and Graecopithecus would only represent an offshoot that dispersed out of Africa very early in the evolutionary history of hominins. On the other hand, Graecopithecus might be closely related to Ouranopithecus, with which it has been synonymised for a long time ${ }^{9}$ or to other Eurasian apes, as suggested by previous cladistic analyse ${ }^{10}$. In these cases, the evolutionary root of humankind would definitely remain in Africa.

The re-attribution of Graecopithecus by Fuss et al. ${ }^{1}$ constitutes an important taxonomic and phylogenetic assertion that has critical implications regarding the early evolutionary origin of Hominini. This assertion must be tested using a cladistic analysis as it provides a standardised method that enables one to reconstruct character polarity and tree topology in a repeatable and testable manner. ${ }^{11,12}$ The aim of this short paper is to assess the phylogenetic position of Graecopithecus using a cladistic analysis and to discuss the biogeography of early hominins.

We used Finarelli and Clyde's character matrix ${ }^{4}$, which is itself an updated version of that of Begun et al. ${ }^{13}$, which is the most comprehensive character matrix available that includes Miocene apes and Hominini. Graecopithecus was coded following the description by Fuss et al. ${ }^{1}$ Two characters were added to the matrix in order to account for the discovery of new diagnostic features in Graecopithecus: first, the thickness of the enamel and second, the fusion of the $p_{4}$ roots (see the supplementary material). These two characters were coded using previous reports in the literature. ${ }^{1,6,14}$ As stated by Fuss et al. ${ }^{1}$, fusion of the $p_{4}$ buccal roots sometimes occurs in Pan; however, in order to reflect the rarity of this condition, this character was coded as absent in this taxon. It must be noted that to code this character as variable in Pan does not change the results of the cladistic analysis.

The analysis was run using Proconsul as the outgroup. The data matrix was treated under the assumption of the minimal model of unweighted parsimony, using PAUP.4b1 $1{ }^{15}$ with a branch-and-bound search (an exhaustive search). All characters were treated as unordered and equally weighted. The data matrix is provided in the supplementary material.

The analysis resulted in 15 equally parsimonious trees of 439 steps. The homoplasy index is 0.45 , the retention index is 0.64 and the consistency index $(\mathrm{Cl})$ is 0.55 . The strict consensus is unresolved for the clade unifying Hominini, Graecopithecus, Pan, Gorilla, Pongo, Sivapithecus, Lufengpithecus, Ouranopithecus and Ankarapithecus. Therefore, only the majority consensus is presented in Figure 1. This tree supports a close relationship between Hominini, Pan and Gorilla, to the exclusion of Graecopithecus, therefore rooting the evolutionary origin of humankind in Africa. Graecopithecus appears to be in an unresolved position. Nevertheless, among the 15 equally parsimonious trees, Graecopithecus appears as the sister taxon of Hominini in four of them. Two characters support this relationship, but they are both subject to homoplasy:

- 100 (changes to state 2, ambiguous, $\mathrm{Cl}$ : 0.50): reduced canine

- 113 (changes to state 1 , ambiguous, $\mathrm{Cl}$ : 0.33): postcanine dentition larger than anterior dentition

In one of the four trees, there are two additional synapomorphies:

- 112 (changes to state 1, ambiguous, Cl: 0.25): low dentine penetrance

- 201 (changes to state 1, ambiguous, Cl: 0.33): thickened enamel

The presence of Tome's root (character 202) appears as an unambiguous synapomorphy only in accelerated transformation optimisation (ACCTRAN scenario). In this respect, it is noticeable that numerous authors have emphasised the importance of homoplasies in Miocene apes, including dental morphology. ${ }^{6,16}$ This analysis highlights some of the characters recognised by Fuss et al. ${ }^{1}$ to identify Graecopithecus as a Hominini in some of the phylogenetic trees, but remarkably reconstructs none of them as a definite, unambiguous synapomorphy. 


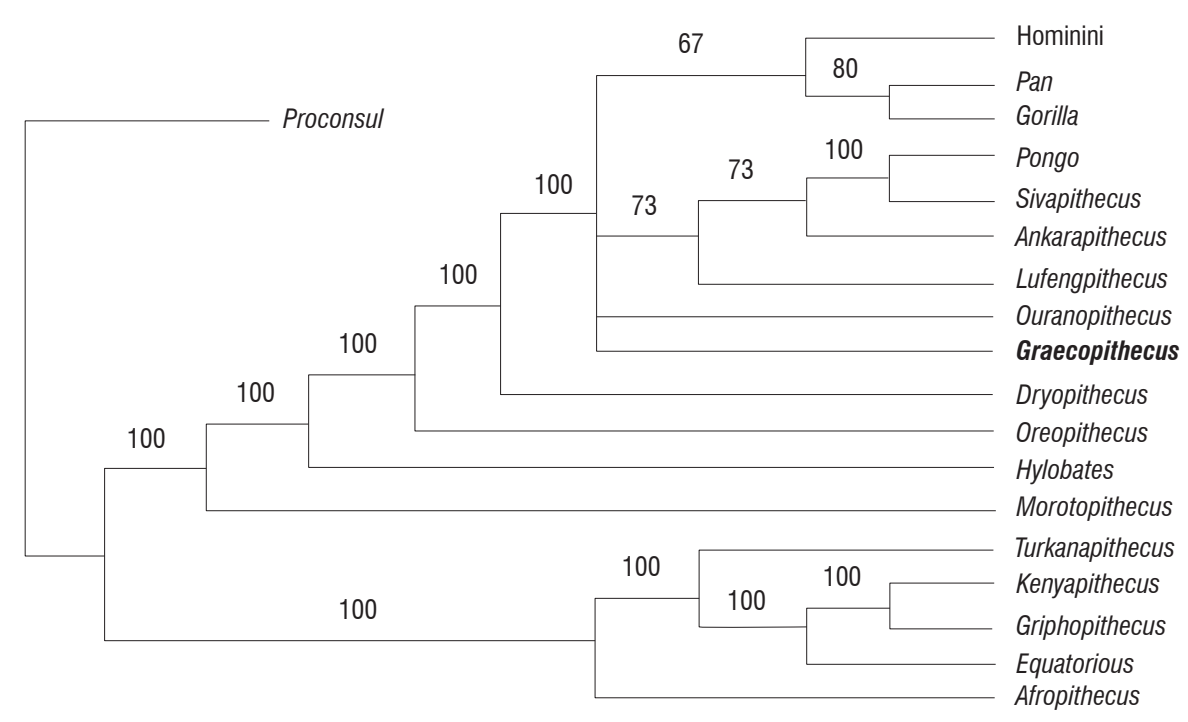

Figure 1: Majority rule consensus of the cladistic analysis performed in this study. Numbers on branches indicate the frequency (\%) of the clade among the 15 most parsimonious trees. Graecopithecus appears in an unresolved position which indicates that it is either reconstructed as a Ponginae or a Homininae.

With 4 trees among 15 supporting a sister-group relationship between Hominini and Graecopithecus, we recognise a small signal for placing Graecopithecus at the root of the Hominini clade. This means that the phylogenetic relationship between Graecopithecus and Hominini is as yet not confirmed. Our analysis supports the view that Graecopithecus is potentially an important taxon for the origin of Hominini, but this is not certain and deserves further investigation and more material.

\section{Acknowledgements}

We thank the National Research Foundation (South Africa), the Claude Leon Foundation, the DST-NRF Centre of Excellence for the Palaeosciences, and the Andrew W. Mellon Foundation for support.

\section{References}

1. Fuss J, Spassov N, Begun DR, Böhme M. Potential hominin affinities of Graecopithecus from the Late Miocene of Europe. PLoS ONE. 2017;12(5), e0177127, 23 pages. https://doi.org/10.1371/journal.pone.0177127

2. Benoit J. There's not enough evidence to back the claim that humans originated in Europe. The Conversation Africa. 2017 May 25; Science and Technology. Available from: https://theconversation.com/theres-not-enoughevidence-to-back-the-claim-that-humans-originated-in-europe-78280

3. Hawks J. Features of the Grecian ape raise questions about early hominins. John Hawks Weblog. 2017 May 22. Available from: http://johnhawks.net/ weblog/fossils/miocene/graecopithecus/graecopithecus-fuss-2017.html

4. Finarelli JA, Clyde WC. Reassessing hominoid phylogeny: Evaluating congruence in the morphological and temporal data. Paleobiology. 2004;30:614651. https://doi.org/10.1666/0094-8373(2004)030<0614:RHPECl> 2.0.C0;2

5. Moyà-Solà S, Köhler M, Alba DM, Casanovas-Vilar I, Galindo J. Pierolapithecus catalaunicus, a new Middle Miocene great ape from Spain. Science. 2004;306(5700):1339-1344. https://doi.org/10.1126/science.1103094

6. Begun DR. Fossil record of Miocene hominoids. In: Henke W, Tattersall I, editors. Handbook of paleoanthropology. Berlin: Springer; 2015. p. 12611332.
7. Berger LR, Hawks J, Dirks P, Elliott M, Roberts EM. Homo naledi and Pleistocene hominin evolution in subequatorial Africa. eLife. 2017;6:e24234, 19 pages. https://doi.org/10.7554/eLife.24234

8. Hawks J, Berger LR. The impact of a date for understanding the importance of Homo naledi. Trans Roy Soc S Afr. 2016;71:125-128. http://dx.doi.org/10. 1080/0035919X.2016.1178186

9. Begun DR. European hominoids. In: Hartwig WC, editor. The primate fossil record. Cambridge, UK: Cambridge University Press; 2002. p. 339-407.

10. Begun DR. Dryopithecins, Darwin, de Bonis, and the European origin of the African apes and human clade. Geodiversitas. 2009;31:789-816. https://doi. org/10.5252/g2009n4a789

11. Darlu P, Tassy, P. La reconstruction phylogénétique. Concepts et methods [Phylogenetic reconstruction. Concepts and methods]. Paris: Masson et Cie; 1993. French.

12. Wiley EO, Siegel-Causey D, Brooks DR, Funk VA. The compleat cladist: A primer of phylogenetic procedures (special publication, no. 19). Lawrence, KS: University of Kansas Museum of Natural History; 1991.

13. Begun DR, Ward CV, Rose MD. Events in hominoid evolution. In: Begun DR, Ward CV, Rose MD, editors. Function, phylogeny, and fossils: Miocene hominoid evolution and adaptations. New York: Plenum Press; 1997. p. $389-415$.

14. Alba DM, Fortuny J, Moyà-Solà $S$. Enamel thickness in the Middle Miocene great apes Anoiapithecus, Pierolapithecus and Dryopithecus. Proc R Soc B. 2010;277(1691):2237-2245. https://doi.org/10.1098/rspb.2010.0218

15. Swofford DL. PAUP*: Phylogenetic analysis using parsimony (and other methods). Version 4. Sunderland, MA: Sinauer Associates; 2002.

16. Delezene LK, Lucas K, Schrein CM. Is Ouranopithecus macedoniensis a hominin? A critical assessment of evidence from canine and $P_{3}$ morphology. In: Abstracts of the Annual Meeting of the American Association of Physical Anthropologists; 2005 April 6-9; Milwaukee, WI, USA. A10. 